\title{
Supporting struggling students on placement: A practical guide
}

\author{
Jo Finch, 2017 \\ Policy Press, Bristol, UK \\ ISBN 978-1447328735, pp. 140, paperback, NZD20.00
}

$\mathrm{T}$ This book, as its title suggests, is focused, first and foremost, on assisting staff whose job it is to support, teach, coach, mentor and assess students in professional field practice settings. It is informed by Jo Finch's 2003 $\mathrm{PhD}$ thesis which explored experiences of practice educators working with failing or struggling students, drawing from international and allied professions. The book is also influenced by a number of Finch's professional experiences as a social work practitioner and practice educator, a social work lecturer and programme leader of an MA in social work programme and currently a module leader for the UK Stage Two Practice Educators Professional Standards.

Although the terminology used is drawn from the English social work education setting, it was not at all difficult to recognise and relate the content and issues to the current experiences we share in the context of social work qualifying programmes in Aotearoa New Zealand. We are more likely to use the terms field educator or field supervisor than practice educator, however, all the discussions and exploration of issues, theory and strategies presented were, I felt, both relevant and useful for our own field educators in NGO and statutory social work service delivery settings. Schools of social work practicum co-ordinators, tutors and academic staff working with all students on their field placements will, I believe, find this book very useful in supporting their work.

The style of this book is informal and it is presented in five topical chapters of approximately 20 pages each and a conclusion. Finch offers a variety of reflective exercises, case vignettes, a learning check and further recommended reading in each chapter, all of which are of practical use to the reader. Her chapters, as listed below, can stand alone and offer excellent topics for peer exploration and further discussion:

1. The context of practice learning and assessment across professions.

2. How do we know when a student is failing to achieve the required standards?

3. The emotional impact of working with a struggling student.

4. Assessment and strategies for working effectively with struggling students.

5. Working constructively with key stakeholders in social work education.

Key issues that we share are explored, such as "quantity and quality of placements" and "reluctance of practice educators to fail students". Jo also highlights a perception in England of low failure rates on student field placements, an issue which has recently been raised by one of our ministers here as an area of concern.

The dilemma of labelling students who are experiencing difficulty on placement or struggling to meet professional requirements (or both) is explored in Chapter Three. This includes the emotional challenges of the practice educator role in relation to our social work professions' values and belief in people's capacity to change and how that impacts our work with students. Another key theme throughout the book 
explores why practice educators may sometimes "miss seeing" or "see but are unable to address" student issues that are professionally problematic.

In Chapter Two (on p. 39) is a useful list of what we might take notice of to identify a student at risk of failing a placement-the areas that students were not well engaged in, or were unable to begin to demonstrate progress in-that could be cause for further exploration and attention. The issues around disproportionate fails and the relatively slow progression in certain student groups are raised. Finch states that this "...highlights ongoing structural oppression and discrimination as well as individual racist practices that serve only to let down both students and the profession" (p. 44).

Chapter Three invites us to recognise the emotional toll that working with a potentially failing student (and failing, or failing to fail) a student has on field/ practice educators. Psychodynamic theory is explored and applied in order to assist understanding our responses in learning and teaching situations. I found this to be a very powerful chapter that I will return to for more reflection and self-discovery;
I can envisage further collegial and team discussions arising from this work.

Chapter Four has good discussion and suggestions on teaching and learning tools for practice educators to use with their students. In relation to a student assessment report, suggestions are made regarding the content and format that reinforce a transparent, fair and balanced account of the placement and final recommendation.

I was particularly drawn to the Chapter Five discussion and exploration of power and reflective exercises on understanding power and authority. This chapter also offered identification of 10 essential building blocks for constructive working relationships between all parties that are involved in the student field education experience.

I would recommend this book to all who are involved in field education with students. It offers relevant research, directed reflection and explorations of how to best be aware of, take care of and support all parties vested in student learning. It encourages and presents a thoughtful and challenging framework to undertaking and assessing students' placement in the field in a "safe, fair, transparent and confident manner" (p. 7). 